\title{
Incidence and Predictive Factors for Orthopedic Surgery in Patients with Psoriatic Arthritis
}

\author{
Tone Wikene Nystad 10 , Yngvil Solheim Husum, Ove Nord Furnes, and Bjørg-Tilde Svanes Fevang
}

\begin{abstract}
Objective. To investigate the incidence of orthopedic procedures in patients with psoriatic arthritis (PsA), and how patient characteristics, time of diagnosis, and treatment affect the need for surgery. Methods. We reviewed the medical history of 1432 patients with possible PsA at Haukeland University Hospital in Bergen, Norway. There were 590 patients (mean age 49 yrs, 52\% women) who had sufficient journal information and a confirmed diagnosis of PsA, and who were included in the present study. Relevant orthopedic procedures were obtained from the hospital's administrative patient records. Survival analyses were completed to evaluate the effect of different factors such as year of diagnosis, age, sex, radiographic changes, disease activity, and treatment, on the risk of surgery. Results. There were 171 procedures (25\% synovectomies, $15 \%$ arthrodesis, and $53 \%$ prostheses) performed on 117 patients. These factors all increased the risk of surgery: female sex [relative risk (RR) $1.9, \mathrm{p}=0.001$ ], age $\geq 70$ years at diagnosis (RR 2.4, $\mathrm{p}=0.001$ ), arthritis in initial radiographs (RR 2.2, $\mathrm{p}=0.006)$, and maximum erythrocyte sedimentation rate $30-59 \mathrm{~mm} / \mathrm{h}(\mathrm{RR} 1.6, \mathrm{p}=0.026)$. Time period of diagnosis had no effect on the outcome. In a subanalysis of surgery exclusive of hip and knee arthroplasty, diagnosis in earlier years (1954-1985 vs 1999-2011) was a risk factor (RR $2.1, \mathrm{p}=0.042)$. Antirheumatic treatment changed significantly over time.

Conclusion. There were $20 \%$ of patients with PsA who needed surgery. We found that the prognosis of patients with PsA did not change regarding the risk of orthopedic surgery, despite the change in treatment. A possible explanation is the increase in large joint replacements in the general population. (First Release September 1 2018; J Rheumatol 2018;45:1532-40; doi:10.3899/jrheum.180203)
\end{abstract}

Key Indexing Terms:

PSORIATIC ARTHRITIS ORTHOPEDIC PROCEDURE PROGNOSIS EPIDEMIOLOGY

Psoriatic arthritis (PsA) develops in up to $30 \% \%^{1,2}$ of patients with psoriasis, and the prevalence worldwide has been estimated between $0.02 \%$ and $0.25 \% \%^{3,4,5,6,7}$. A study of the population of Hordaland county in western Norway, which is the population we address in this study, found a prevalence of $0.2 \%$, and polyarthritis was the most frequent subclass, documented in $68.6 \%^{8}$.

PsA with peripheral joint involvement is a progressive disease in most patients ${ }^{9}$, and erosions are seen in $47 \%$ within the first 2 years ${ }^{10}$. Individuals with polyarthritis are the most susceptible to bone erosions and deformities ${ }^{11}$. Previous

From the Bergen group of Epidemiology and Biomarkers in Rheumatic Disease, Department of Rheumatology, Haukeland University Hospital; The Norwegian Arthroplasty Register, Department of Orthopaedic surgery, Haukeland University Hospital; Departments of Clinical Medicine (K1) and Clinical Science (K2), University of Bergen, Bergen, Norway.

This work was funded by the Western Norway Regional Health Authority. T.W. Nystad, MD, Bergen group of Epidemiology and Biomarkers in Rheumatic Disease, Department of Rheumatology, Haukeland University Hospital; Y.S. Husum, MD, The Norwegian Arthroplasty Register, Department of Orthopaedic surgery, Haukeland University Hospital; O.N. Furnes, PhD, Department of Clinical Medicine (K1), University of Bergen; B.T. Fevang, PhD, Department of Clinical Science (K2), University of Bergen.

Address correspondence to Dr. T.W. Nystad, Haukeland University Hospital, Department of Rheumatology, Box 1400, Bergen 5021, Norway. E-mail: tone.wikene.nystad@helse-bergen.no

Accepted for publication June 22, 2018. studies have been conflicting regarding whether PsA is as destructive radiologically as rheumatoid arthritis (RA) $)^{6,12}$.

Spontaneous remission of PsA is rare $^{13}$, and if nonsteroidal antiinflammatory drugs (NSAID) and intraarticular steroids are not sufficient, a synthetic disease-modifying antirheumatic drug (DMARD) is often prescribed to ease pain and restore function. No synthetic DMARD has, however, been proven to slow or prevent radiographic changes. Biologic treatment is recommended when other agents are not sufficient, and it has been shown to give better control of structural damage ${ }^{14,15}$.

Orthopedic surgery has been a necessary part of treating patients with PsA when medication fails to prevent inflammation and joint destruction. Surgery can thus be considered a proxy for the degree of inflammatory activity, and studying time trends in orthopedic surgery gives valuable information regarding the prognosis of patients with inflammatory arthritis. In previous studies, there is a large discrepancy in the incidence of orthopedic surgery in patients with PsA. A study of 444 patients published in 1998 found that $7 \%$ had a musculoskeletal procedure performed ${ }^{16}$. In a more recent study of 269 patients published in 2016, 48.3\% received orthopedic surgery ${ }^{17}$. This total, however, also included arthroscopies, meniscus surgery, carpal tunnel surgery, surgery of the spine, and others (205 of 280 procedures) ${ }^{18}$. We have not found any data on changes over time. In patients

Personal non-commercial use only. The Journal of Rheumatology Copyright $\odot$ $)$ 2018. All rights reserved 
with RA there has been a gradual declining incidence of orthopedic interventions ${ }^{19}$. The change in available medical treatment is believed responsible for this ${ }^{20,21}$. Because synthetic DMARD may be less efficient in patients with PsA, it is uncertain whether a decline of the same magnitude can be expected among these patients. It is also possible that a change, if present, would occur later, after the introduction of tumor necrosis factor (TNF)- $\alpha$ inhibitors in this patient group.

We investigated the occurrence of orthopedic surgery among patients diagnosed with PsA in western Norway, and whether patient characteristics, treatment, and year of diagnosis affected the need for surgical intervention.

\section{MATERIALS AND METHODS}

Our data originate from Haukeland University Hospital, which delivers specialist care to about 500,000 inhabitants in western Norway. Because only 2 private practicing rheumatologists operate in the area, the vast majority of patients with rheumatic disease are cared for by the hospital's department of rheumatology. In general, patients are referred to specialist care at the time of suspected inflammatory rheumatic disease. Some patients with stable disease are later managed by their general practitioner, but most continue to be followed until death or inactive disease.

From the hospital's administrative patient records, we have data available from 1972 until the present, and some paper files go back even further. Using the International Classification of Diseases (ICD) 8th, 9th, and 10th revisions, we searched for disease codes for PsA (ICD-10 L40.5, ICD-9 7133), and the combination of arthritis or spondyloarthritis (SpA; ICD-10 M06, M46; ICD-8 712, 715; ICD-9 714) and psoriasis (ICD-10 L40, ICD-8/ICD-9 696). Because orthopedic surgery is a late outcome, we wished to give all patients the possibility of at least 5 years observation after the date of diagnosis and excluded patients with first hospital contact later than 2011. The number of patients with first contact in the pre-methotrexate (MTX) era (before 1985) and in the era after the introduction of MTX, but before the use of TNF- $\alpha$ inhibitors (1986-1998), was much lower than the number of patients with first contact from 1999 to 2011. To ensure a sufficient number of patients from the first 2 periods, we chose to evaluate all of these, to find possible subjects for inclusion. From the third period, we evaluated patients with at least 2 hospital contacts, to increase the possibility that cases evaluated had a confirmed diagnosis of PsA and could be included in the study. However, the inclusion criteria were the same for all evaluated patients. We also searched the local patient system GoTreatIt and the National Arthritis Registry (NorArthritis; helse-bergen.no/seksjonengelsk/seksjon-avdeling/Sider/Norwegian-Arthritis-Registry-NorArthritis.aspx) for patients registered under the diagnosis psoriatic arthritis.

Using these sources, 2251 patients remained for evaluation. All of these had contacts with Haukeland University Hospital from 1972 to 2011 coded in accordance with our search, but some had no contact with the department of rheumatology prior to 2012, and others did not consent to participation. There were 819 patients excluded because of this, leaving 1432 patients available for journal review. Of these, 951 had given consent to participate and 481 had died. Following this process, we were able to include 590 patients. The selection process is described in Figure 1. The search performed was very broad, to account for the possibility that in previous years, patients with PsA were not identified and coded that way, but rather as other arthritis conditions. This proved not to be true, and the vast majority of patients included had been identified and coded as PsA.

Each medical record was reviewed for the following information: weight, height, year of diagnosis, number of joints with arthritis (evaluated by the treating rheumatologist) during disease course, whether in fulfillment of the ClASsification for Psoriatic ARthritis criteria (CASPAR), the presence of psoriatic dermatitis, and erythrocyte sedimentation rate (ESR) at diagnosis and maximal levels. The medical records did not contain radiographic images, so only the radiologist's interpretation of these as normal or consistent with arthritis or osteoarthritis (OA) was recorded, and for images of the columnar and sacroiliac joints (SIJ), whether there were signs of SpA. Medications used in the first year and during the course of the disease were also registered. Supplementary data were obtained from the Norwegian Arthritis Registry for patients herein. The study was approved by the Regional Committee for Medical and Health Research Ethics (2016/2207/REK West).

Because MTX was introduced to our patient group around 1986, and biologic treatment in the form of TNF- $\alpha$ inhibitors in 1999, we split the group into 3 depending on diagnosis in different treatment eras: time period 1 included patients diagnosed prior to 1986, time period 2 from 1986 to 1998, and time period 3 from 1999 to 2011. Patient characteristics for each group and in total are described in Table 1. Mean body mass index (BMI) was significantly lower in time period 1 versus time period $3(p=0.033)$. Mean age at disease onset was significantly older in time period 2 than in time periods 1 and 3. Mean maximum ESR during disease course was significantly higher in patients in time periods 1 and 2 versus time period 3 . For $56 \%$ of patients, radiographic examination of SIJ was present, and $62 \%$ of journals contained radiographic examination of the spine. If we assume that when pictures were not taken, the patient did not have symptoms from axial joints, and presumably no axial arthritis, $19 \%$ of patients had sacroiliitis and/or SpA (radiographic SIJ arthritis 14\% and radiographic SpA 9\%).

Surgical procedures. For the selected 590 patients, information on orthopedic surgery was obtained from the hospital's administrative patient records and the Norwegian Arthroplasty Register (NAR). NAR was established in 1987, initially as a register of total hip replacements, but has since 1994 been a register of all artificial joints in the Norwegian population. Haukeland University Hospital's administrative patient system has registered all performed procedures since 1972, and the data from NAR gave extra security for completeness of data in the years since the register's establishment. The archives of 2 other local hospitals, which up until the early 1990s performed some surgery in this patient group, were also investigated. We searched for synovectomies, arthrodesis, and prosthesis procedures using coding systems NOMESCO Classification of Surgical Procedures, and that of the Norwegian Institute of Public Health.

Statistical analysis. Descriptive statistics were used for presentation of the patient characteristics. Unpaired $t$ test for continuous variables and chi-square test for categorical data were used. Person-time was accumulated from PsA diagnosis until the first occurrence of orthopedic surgery, death, or the end of the study period (July 30,2017). Cumulative incidence rates were calculated for the entire study period as the number of events per 100 patient-years. Because followup duration was different for individual patients, the effect of different factors on the risk for undergoing surgery was analyzed using Kaplan-Meier plots and Cox regression analyses. A directed acyclic graph (model code in Supplementary Data 1, available with the online version of this article $)^{22}$ was constructed to determine which variables should be included in the multivariate Cox proportional hazards regression model for each factor. Unless otherwise stated, analyses included all subjects, and the outcome was the first occurrence of arthroplasty, arthrodesis, or synovectomy. We also performed subanalysis of factors affecting the risk of surgery exclusive of hip and knee arthroplasty. All analyses were done on the original files, as well as on files with multiple imputation of missing values (100 files).

We investigated the effect of these patient characteristics on the risk for undergoing surgery: age at diagnosis, sex, time period of diagnosis, number of affected joints $(<4 \mathrm{vs} \geq 5), \mathrm{BMI} \geq 30$, first ESR, highest ESR during disease course, radiographic changes at diagnosis, use of MTX within 2 years of disease onset, use of biologic treatment within 2 years of disease onset, and fulfillment of the CASPAR criteria for PsA. Because psoriatic dermatitis was present in $94 \%$ of the patients, no further analysis of this exposure variable was performed.

Statistical analyses were performed in SPSS versions 23 and 24. The level for statistical significance was set to $\mathrm{p}<0.05$.

Personal non-commercial use only. The Journal of Rheumatology Copyright @) 2018. All rights reserved. 


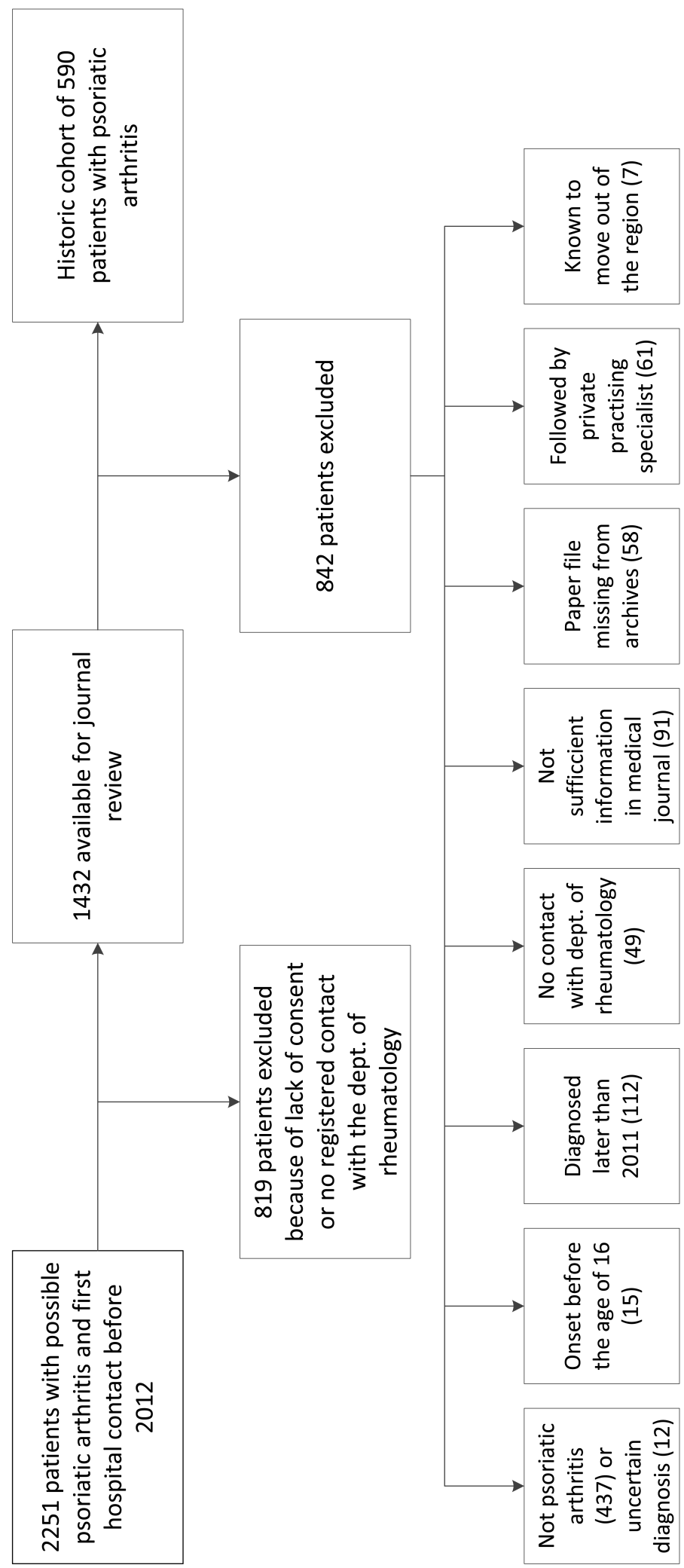

Figure 1. Selection process. 
Table 1. Patient characteristics in each time period and in total.

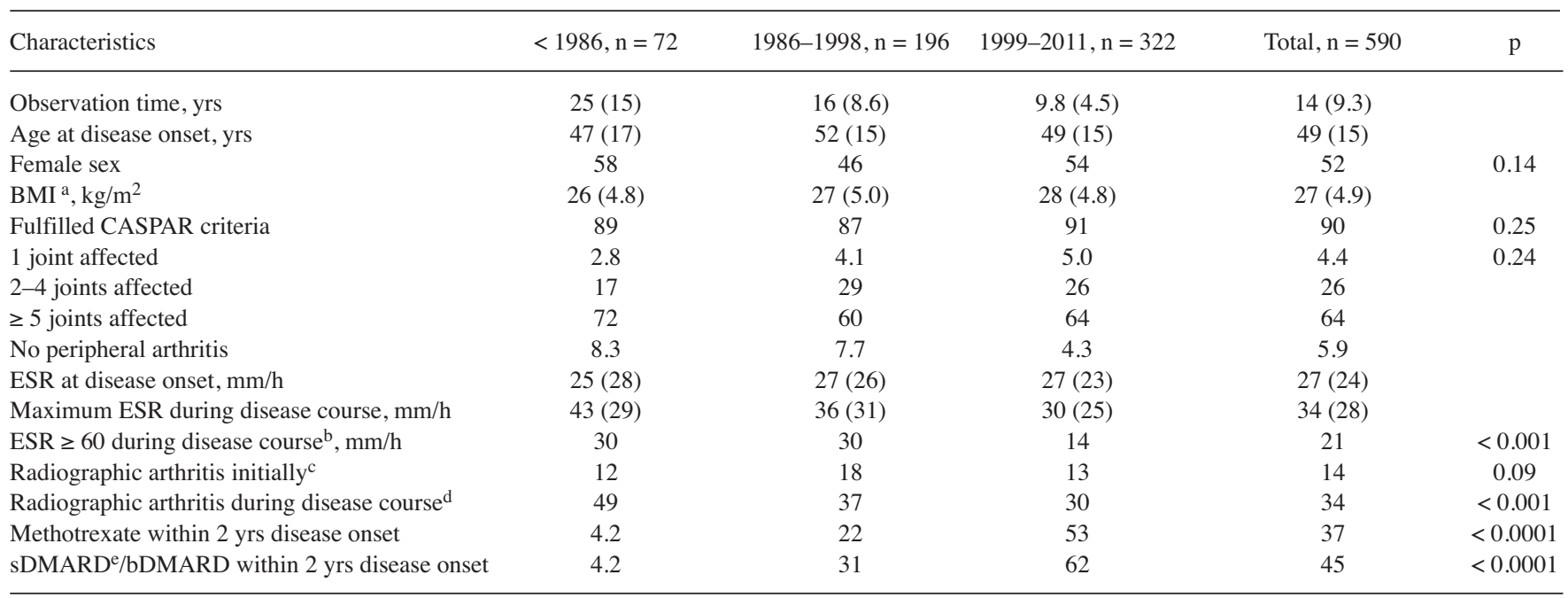

Data are $\%$ or mean (SD) unless otherwise specified. ${ }^{\mathrm{a}}$ Available for 459 patients. ${ }^{\mathrm{b}}$ Among available (506). ${ }^{\mathrm{c}}$ Percentage among patients with initial radiographic examination (470 in total). ${ }^{\mathrm{d}}$ Percentage among patients with radiographic examination later in disease course (434 in total). ${ }^{\mathrm{e}}$ Defined as sulfasalazine, methotrexate, or leflunomide. BMI: body mass index; CASPAR: CIASsification for Psoriatic ARthritis criteria; ESR: erythrocyte sedimentation rate; sDMARD: synthetic disease-modifying antirheumatic drug; bDMARD: biologic DMARD.

\section{RESULTS}

Treatment, presented as percentage of patients given each medication in the first year and during the course of the disease is presented in Figure 2. The proportion of patients using NSAID was high in all 3 time periods, but significantly higher in time period 1, both in the first year and during the course of the disease. Within 2 years of disease duration, 37\% of all patients had been prescribed MTX. There were 56\% who were prescribed MTX during the course of the disease. The proportion of patients receiving MTX within the first year since diagnosis increased from $17 \%$ in time period 2 to $43 \%$ in time period 3 . When looking only at patients in time period 3, 53\% were prescribed MTX, and 19\% biologics within 2 years of disease, and 36\% had used biologic treatment during disease course. Further details are described in Table 1.

The department of dermatology seemed to start using MTX earlier than the department of rheumatology in our county, and the 3 patients in time period 1 using MTX in the first year of disease had all been prescribed this from their dermatologist.

There was no significant difference in the prescription of effective medication in patients aged $\geq 70$ years versus younger patients.

Surgical procedures. There were 1.4 events per 100 patient-years over the whole study period. When excluding surgery conducted earlier than 1 year prior to diagnosis, we found 171 procedures performed in 117 patients (20\%). The procedures performed within 1 year prior to diagnosis were counted as performed at diagnosis, because we had reason to assume an association between surgery and diagnosis. A single procedure was performed on $68 \%$, and $24 \%$ who had
2 procedures performed, whereas $9.5 \%$ underwent 3-6 surgeries. Of the types of procedures, $53 \%$ of the 171 procedures were prosthetic, $25 \%$ were synovectomies, and $15 \%$ arthrodesis procedures (triple arthrodeses and forefoot procedures included). The distribution of different procedures in diverse joints is described in Table 2 . The most frequently operated area was the knee, in which $38 \%$ of procedures were performed, followed by the hip (27\%). Eight percent of the 590 patients had knee surgery performed, $6.4 \%$ who had hip surgery, and $6.1 \%$ who had surgery of the hands or feet. Mean time to first procedure was 8.5 years $(0-52 \pm$ SD $8.5 \mathrm{yrs})$. Mean age at surgery was 62 years. Patients were youngest at time of synovectomy (mean age 45 yrs), older at first arthrodesis procedure (mean age $55 \mathrm{yrs}$ ), and oldest at arthroplasty surgery (mean age 70 yrs).

Survival analyses. Results are presented in Table 3 and Figure 3 . Factors found to affect the risk of a surgical procedure during the course of the disease were older age at diagnosis, female sex, arthritis on initial radiographs, and highest ESR between 30 and $59 \mathrm{~mm} / \mathrm{h}$. Time period of diagnosis did not influence the risk. No significant effects were found involving fulfillment of the CASPAR criteria, biologic treatment within 2 years of disease onset, MTX treatment within 2 years of disease onset, ESR at disease onset, $\geq 5$ versus $\leq 4$ joints affected, or $\mathrm{BMI} \geq 30 \mathrm{~kg} / \mathrm{m}^{2}$. OA in initial radiographs was borderline significant, but not significant when analyzing 100 files with imputed values [relative risk (RR) $1.4,95 \%$ CI $0.72-2.64, \mathrm{p}=0.33$ ]. For the other exposure variables, analysis of the files with imputed values did not change the significance of the above-described results.

When performing subanalyses of procedures exclusive of

$$
\text { Personal non-commercial use only. The Journal of Rheumatology Copyright } \subset \text { } 2018 \text {. All rights reserved. }
$$


A
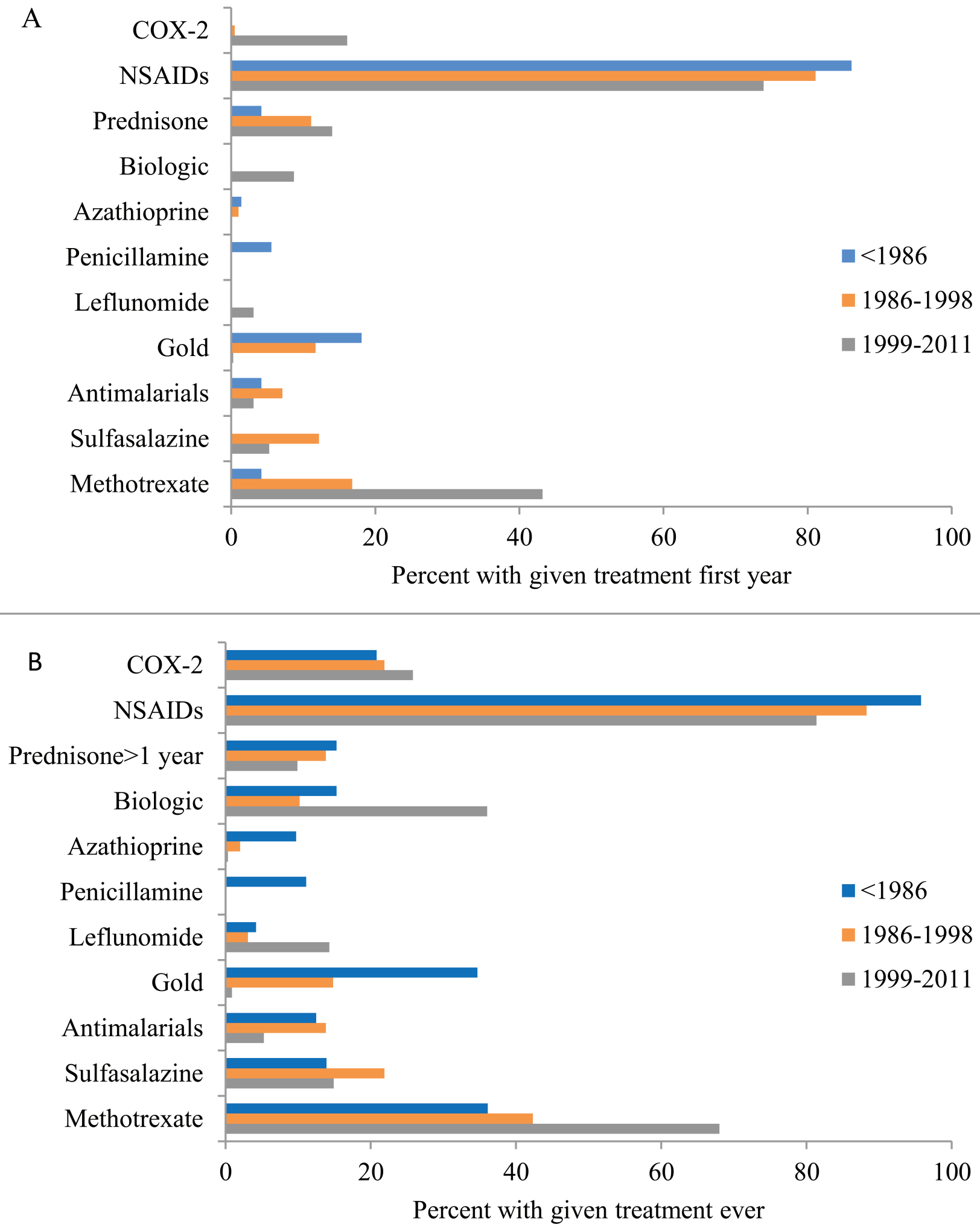

Figure 2. Medical treatment in the first year (A) and during the course of the disease (B) for patients diagnosed in 3 different time periods. COX-2: cyclooxygenase 2 inhibitors; NSAID: nonsteroidal antiinflammatory drugs. 
Table 2. Type and localization of surgical interventions.

\begin{tabular}{lccc}
\hline Procedure & Joint Area & N & \% of Total \\
\hline Arthroplasties & Shoulder & 2 & 1.2 \\
& Hip & 47 & 27 \\
& Knee & 41 & 24 \\
Synovectomies & Foot & 1 & 0.6 \\
& Elbow & 2 & 1.2 \\
& Wrist/hand & 10 & 5.8 \\
Arthrodeses & Knee & 23 & 13 \\
& Ankle/foot & 7 & 4.1 \\
& Wrist/hand & 11 & 6.4 \\
Other/unknown & Foot & 13 & 7.6 \\
& Unknown (hand/foot) & 1 & 0.6 \\
& Wrist/hand & 4 & 2.3 \\
Total & Knee & 2 & 1.2 \\
& Ankle/foot & 7 & 4.1 \\
& & 171 & 100 \\
\hline
\end{tabular}

hip and knee prostheses (61 patients), we found that patients diagnosed 1954-1985 had an increased risk of surgery (RR $2.1,95 \%$ CI $1.03-4.18, \mathrm{p}=0.042$ ) compared to patients diagnosed 1999-2011. Diagnosis in the years 1986-1998 was not a significant risk factor (RR $1.5,95 \%$ CI $0.83-2.72$, $\mathrm{p}=0.18)$. Highest ESR $30-59 \mathrm{~mm} / \mathrm{h}(\mathrm{RR} 3.4,95 \%$ CI $1.8-6.4, \mathrm{p}<0.001)$ and $\mathrm{ESR} \geq 60 \mathrm{~mm} / \mathrm{h}(\mathrm{RR} 2.4,95 \% \mathrm{CI}$ $1.1-5.0, \mathrm{p}=0.025)$ increased the risk of surgery. Analyzing 100 files with imputed values did not change the significance of the above-described results, and we did not find other factors that significantly affected the outcome.

\section{DISCUSSION}

Our study's main findings were that $20 \%$ of patients with PsA required orthopedic surgery, and that time period of diagnosis did not affect the outcome.

Observational studies have disadvantages, compared to randomized controlled trials (RCT), but describe to a greater extent the prognosis of patients in real life instead of patients treated under ideal conditions. In this study we observed the patients for a mean time of $13.8(0-63)$ years, which would be impossible in an RCT because it is less suitable for the investigation of late outcomes.

Female sex, older age, elevated ESR, and arthritis in initial radiographs increased the risk of orthopedic surgery. Others have also found that female sex predicts an unfavorable outcome ${ }^{23,24}$, whereas in a different study, male sex was a risk factor for early radiographic damage ${ }^{25}$. For orthopedic surgery exclusive of hip and knee prostheses, patients diagnosed in time period 1 (1954-1985) had an increased risk of surgery compared to those with a diagnosis in time period 3 (1999-2011).

We divided patients into 3 time periods based on the availability of medical treatment at diagnosis. A limitation to this approach is that the change in treatment came gradually, and that new treatment was also made available to patients diagnosed in previous years, although later in the disease course.

Among patients diagnosed in the 3 time periods, we did not find any significant changes in the disease activity as measured by inflammatory variables or radiographic changes,

Table 3. Percent operated at 5 and 10 years disease duration, among patients at risk, and relative risk (RR) of surgery according to major explanatory factors.

\begin{tabular}{|c|c|c|c|c|c|}
\hline Variables & 5 Years & 10 Years & $\mathrm{RR}$ & $95 \% \mathrm{CI}$ & $\mathrm{p}$ \\
\hline \multicolumn{6}{|l|}{ Age* } \\
\hline$<70$ & 8.2 & 13 & 1 & & \\
\hline$\geq 70$ & 22 & 32 & 2.4 & $1.5-4.1$ & 0.001 \\
\hline \multicolumn{6}{|l|}{ Sex** } \\
\hline Male & 7.6 & 11 & 1 & & \\
\hline Female & 11 & 18 & 1.9 & $1.3-2.8$ & 0.001 \\
\hline \multicolumn{6}{|l|}{ Radiographic changes at diagnosis ${ }^{\dagger}$} \\
\hline No arthritis & 6.9 & 13 & 1 & & \\
\hline Possible arthritis, or MR findings only & 12 & 15 & 1.4 & $0.58-3.3$ & 0.45 \\
\hline Arthritis & 15 & 30 & 2.2 & $1.3-4.0$ & 0.006 \\
\hline Osteoarthritis & 19 & 19 & 2.0 & $0.999-3.9$ & 0.050 \\
\hline \multicolumn{6}{|l|}{ Highest ESR, $\mathrm{mm} / \mathrm{h}^{\dagger \dagger}$} \\
\hline$<30$ & 7.1 & 10 & 1 & & \\
\hline $30-59$ & 12 & 20 & 1.6 & $1.1-2.5$ & 0.026 \\
\hline$\geq 60$ & 11 & 18 & 1.5 & $0.93-2.5$ & 0.095 \\
\hline \multicolumn{6}{|l|}{ Time period $* *$} \\
\hline 1999-2011 & 9.4 & 13 & 1 & & \\
\hline $1986-1998$ & 9.4 & 16 & 1.1 & $0.75-1.8$ & 0.52 \\
\hline$<1986$ & 9.8 & 17 & 1.2 & $0.69-2.0$ & 0.54 \\
\hline
\end{tabular}

$*$ Adjusted for sex and time period of diagnosis. ** Unadjusted analysis. ${ }^{\dagger}$ Adjusted for sex, age, time period of diagnosis, no. affected joints ( $<$ or $\geq 5$ ), and BMI $\geq 30$. ${ }^{\dagger}$ Adjusted for time period of diagnosis, sex, age, and no. affected joints $(<$ or $\geq 5)$. MR: magnetic resonance; ESR: erythrocyte sedimentation rate. 


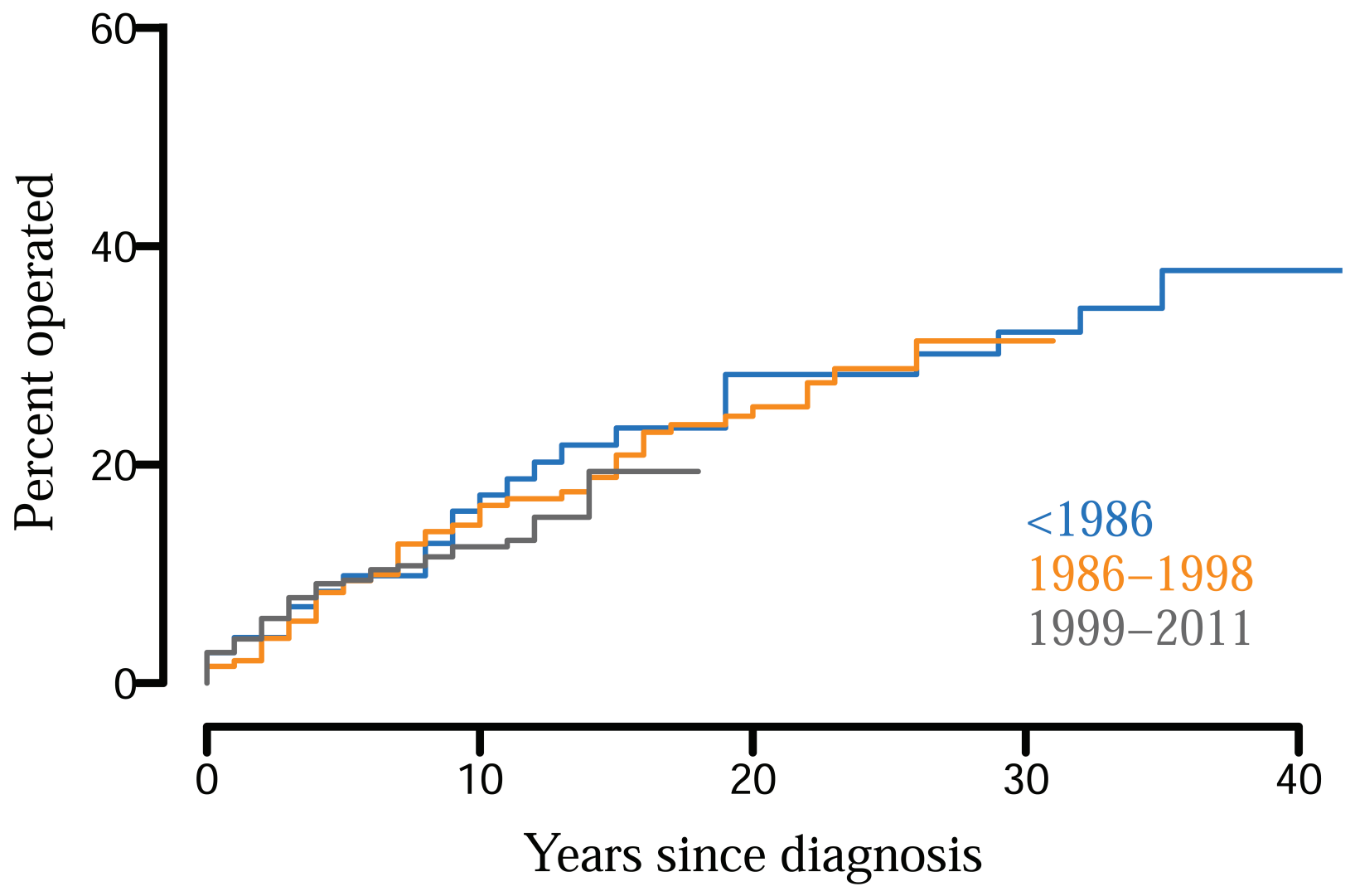

Figure 3. Cumulative percent having surgery, based on 3 different time periods of diagnosis.

at disease onset. On the other hand, maximum ESR during the disease course decreased significantly from 43 to 30 , from time period 1 to time period 3, and the share with ESR $\geq 60$ $\mathrm{mm} / \mathrm{h}$ during the course of the disease fell from $30 \%$ in patients diagnosed before 1986 to $14 \%$ in patients diagnosed 1999-2011 ( $p<0.001)$. Significantly more patients among those diagnosed in earlier years also developed radiographic changes. This suggests that the burden of inflammation has become lower in recent years. In the articles by Zangger, et $a l^{16}$ and Haque, et $a l^{17}$, survival analyses were not performed, but patients were divided into 2 groups according to whether they had undergone orthopedic surgery, and the groups were then compared. Zangger, et al found that patients who had an operation had significantly more radiological damage and more actively inflamed joints at first assessment ${ }^{16}$. Haque, et al found that asymmetric mono-/oligoarticular arthritis and the combination of peripheral and axial disease were more frequent among patients with surgeries, whereas there were no differences in treatment between the groups ${ }^{17}$.

There has been a significant change in the prescription of medication. The share of patients receiving potent medication within 2 years of disease onset more than doubled when comparing patients diagnosed 1999-2011 to patients diagnosed 1986-1998.

When investigating surgery among patients with inflammatory arthritis in our region, we found that $31 \%$ of patients with RA underwent an orthopedic procedure ${ }^{21}$, whereas for patients with PsA, 20\% had joint surgery performed. For RA, diagnosis in earlier years was a significant risk factor for orthopedic surgery. In PsA, however, this did not affect the outcome.

When analyzing only hip and knee arthroplasty, the time period of diagnosis was not a significant risk factor for surgery in patients with $\mathrm{RA}^{21}$. This supports the findings from other studies, that while hand and foot surgery in RA has declined, large joint replacements remain unchanged ${ }^{26}$. A possible explanation for this might be the general increase seen in joint replacement surgery in later years ${ }^{27,28,29}$, but it has also been discussed whether the inflammation process is different in small joints compared to larger joints, and that the latter could be less affected by antirheumatic therapy ${ }^{26,30,31}$. Whereas arthroplasty in joints other than hip and knee were found to be frequent in RA (18\% of prosthesis procedures), this was seldom performed in patients with PsA, where $96 \%$ of prosthesis surgery were hip and knee procedures. Because large joint replacements account for a greater proportion of surgery in patients with PsA than those with RA (51\% vs 33\%), this would be expected to weaken the effect of time period of diagnosis. After excluding prosthesis surgery of the hip and knee from the analysis, we find that diagnosis in 1954-1985 increased the risk of surgery compared to diagnosis later than 1998. 
A possible confounding factor is that hip and knee arthroplasties may have been conducted on the basis of coexisting OA in patients with PsA. The etiology of joint destruction and the subsequent need for joint replacement surgery in patients with inflammatory arthritis may be hard to detect. This is especially the case for the hip joint, particularly before the use of ultrasound. We found that $57 \%$ of patients with knee prosthesis surgery had had arthritis of the knee during disease course, and that $21 \%$ of patients with hip prosthesis surgery had had hip joint arthritis, as detected by the treating rheumatologist. One must thus suspect that inflammatory disease was a contributing factor also for large-joint destruction.

Although not to the same extent as for RA, patients with PsA have, to an increasing degree, been treated with synthetic, and in later years, biologic DMARD ${ }^{32}$. In our study, this change coincides with patients having a lower burden of inflammation, as measured by ESR. Others have found that early referral to an arthritis clinic ${ }^{33}$ and tight disease control ${ }^{34}$ give a better outcome ${ }^{34}$. However, it has been shown that clinical signs of inflammation and progression of joint destruction might be dissociated $25,30,31$, and we could not find a decrease in joint surgery, suggesting that this outcome has not been affected by the change in medication, contrary to what is found for patients with RA. This is in concordance with the knowledge that contrary to the effect of synthetic DMARD on structural damage in patients with RA ${ }^{35}$, the same has not been shown for PsA.

Because biologic treatment has been shown to prevent joint destruction in PsA ${ }^{15}$, it is possible that increasing use of TNF- $\alpha$ inhibitors would lessen the risk of an orthopedic procedure during the disease course. When considering all procedures, this was not the case in our material. Among the $25 \%$ of patients prescribed biologic treatment during the course of the disease, only $42 \%$ started treatment within 2 years of diagnosis. It might thus be that damage, predicting later orthopedic surgery, had already occurred when treatment was initiated ${ }^{17}$.

We found that $20 \%$ of patients with PsA underwent orthopedic surgery. The maximum disease activity seems to have decreased over time, but the risk of surgery was not affected by year of diagnosis. The unchanged prognosis regarding joint surgery in patients diagnosed from 1985 to 1998, compared to those with disease onset in the pre-MTX era, might indicate that MTX and other synthetic DMARD do not prevent joint damage. However, because biologic treatment has been shown to prevent joint damage ${ }^{15}$, one would expect the risk of orthopedic surgery to decline following its introduction, in patients diagnosed from 1999 onward. It is possible that the improved treatment is too recent for a change in prognosis to have become evident. But one must also consider whether the use of biologic treatment might be too infrequent and initiated too late if we seek optimal treatment of patients with PsA.

\section{ONLINE SUPPLEMENT}

Supplementary material accompanies the online version of this article.

\section{REFERENCES}

1. Zachariae H. Prevalence of joint disease in patients with psoriasis: implications for therapy. Am J Clin Dermatol 2003;4:441-7.

2. Villani AP, Rouzaud M, Sevrain M, Barnetche T, Paul C, Richard MA, et al. Prevalence of undiagnosed psoriatic arthritis among psoriasis patients: Systematic review and meta-analysis. J Am Acad Dermatol 2015;73:242-8.

3. Day MS, Nam D, Goodman S, Su EP, Figgie M. Psoriatic arthritis. J Am Acad Orthop Surg 2012;20:28-37.

4. Gladman DD, Antoni C, Mease P, Clegg DO, Nash P. Psoriatic arthritis: epidemiology, clinical features, course, and outcome. Ann Rheum Dis 2005;64 Suppl 2:ii14-7.

5. Goldenstein-Schainberg C, Favarato MH, Ranza R. Current and relevant concepts in psoriatic arthritis. Rev Bras Reumatol 2012;52:98-106.

6. Rahman P, Nguyen E, Cheung C, Schentag CT, Gladman DD. Comparison of radiological severity in psoriatic arthritis and rheumatoid arthritis. J Rheumatol 2001;28:1041-4.

7. Hoff M, Gulati AM, Romundstad PR, Kavanaugh A, Haugeberg G. Prevalence and incidence rates of psoriatic arthritis in central Norway: data from the Nord-Trondelag health study (HUNT). Ann Rheum Dis 2015;74:60-4.

8. Madland TM, Apalset EM, Johannessen AE, Rossebo B, Brun JG. Prevalence, disease manifestations, and treatment of psoriatic arthritis in Western Norway. J Rheumatol 2005;32:1918-22.

9. McHugh NJ, Balachrishnan C, Jones SM. Progression of peripheral joint disease in psoriatic arthritis: a 5-yr prospective study. Rheumatology 2003;42:778-83.

10. Kane D, Stafford L, Bresnihan B, FitzGerald O. A prospective, clinical and radiological study of early psoriatic arthritis: an early synovitis clinic experience. Rheumatology 2003;42:1460-8.

11. Veale D, Rogers S, Fitzgerald O. Classification of clinical subsets in psoriatic arthritis. Br J Rheumatol 1994;33:133-8.

12. Sokoll KB, Helliwell PS. Comparison of disability and quality of life in rheumatoid and psoriatic arthritis. J Rheumatol 2001;28:1842-6.

13. Ritchlin CT, Colbert RA, Gladman DD. Psoriatic arthritis. N Engl J Med 2017;376:2095-6.

14. Goulabchand R, Mouterde G, Barnetche T, Lukas C, Morel J, Combe B. Effect of tumour necrosis factor blockers on radiographic progression of psoriatic arthritis: a systematic review and meta-analysis of randomised controlled trials. Ann Rheum Dis 2014;73:414-9.

15. Mease PJ. Biologic therapy for psoriatic arthritis. Rheum Dis Clin North Am 2015;41:723-38.

16. Zangger P, Gladman DD, Bogoch ER. Musculoskeletal surgery in psoriatic arthritis. J Rheumatol 1998;25:725-9.

17. Haque N, Lories RJ, de Vlam K. Orthopaedic interventions in patients with psoriatic arthritis: a descriptive report from the SPAR cohort. RMD Open 2016;2:e000293.

18. Michet CJ, Mason TG, Mazlumzadeh M. Hip joint disease in psoriatic arthritis: risk factors and natural history. Ann Rheum Dis 2005;64:1068-70.

19. Nystad TW, Fenstad AM, Furnes O, Havelin LI, Skredderstuen AK, Fevang BT. Reduction in orthopaedic surgery in patients with rheumatoid arthritis: a Norwegian register-based study. Scand J Rheumatol 2016;45:1-7.

20. Finckh A, Choi HK, Wolfe F. Progression of radiographic joint damage in different eras: trends towards milder disease in rheumatoid arthritis are attributable to improved treatment. Ann Rheum Dis 2006;65:1192-7. 
21. Nystad TW, Fenstad AM, Furnes O, Fevang BT. Predictors for orthopaedic surgery in patients with rheumatoid arthritis. Scand J Rheumatol 2018;47:282-90.

22. Shrier I, Platt RW. Reducing bias through directed acyclic graphs. BMC Med Res Methodol 2008;8:70.

23. Theander E, Husmark T, Alenius GM, Larsson PT, Teleman A, Geijer M, et al. Early psoriatic arthritis: short symptom duration, male gender and preserved physical functioning at presentation predict favourable outcome at 5-year follow-up. Results from the Swedish Early Psoriatic Arthritis Register (SwePsA). Ann Rheum Dis 2014;73:407-13.

24. Eder L, Gladman DD. Predictors for clinical outcome in psoriatic arthritis - what have we learned from cohort studies? Expert Rev Clin Immunol 2014;10:763-70.

25. Geijer M, Lindqvist U, Husmark T, Alenius GM, Larsson PT, Teleman A, et al. The Swedish Early Psoriatic Arthritis Registry 5-year followup: substantial radiographic progression mainly in men with high disease activity and development of dactylitis. J Rheumatol 2015;42:2110-7.

26. Nikiphorou E, Carpenter L, Morris S, Macgregor AJ, Dixey J, Kiely $\mathrm{P}$, et al. Hand and foot surgery rates in rheumatoid arthritis have declined from 1986 to 2011, but large-joint replacement rates remain unchanged: results from two UK inception cohorts. Arthritis Rheumatol 2014;66:1081-9.

27. Puolakka TJ, Pajamaki KJ, Halonen PJ, Pulkkinen PO, Paavolainen P, Nevalainen JK. The Finnish Arthroplasty Register: report of the hip register. Acta Orthop Scand 2001;72:433-41.

28. Nystad TW, Furnes O, Havelin LI, Skredderstuen AK, Lie SA, Fevang BT. Hip replacement surgery in patients with ankylosing spondylitis. Ann Rheum Dis 2014;73:1194-7.
29. Dixon T, Shaw M, Ebrahim S, Dieppe P. Trends in hip and knee joint replacement: socioeconomic inequalities and projections of need. Ann Rheum Dis 2004;63:825-30.

30. Molenaar ET, Voskuyl AE, Dinant HJ, Bezemer PD, Boers M, Dijkmans BA. Progression of radiologic damage in patients with rheumatoid arthritis in clinical remission. Arthritis Rheum 2004;50:36-42.

31. Kirwan JR. The synovium in rheumatoid arthritis: evidence for (at least) two pathologies. Arthritis Rheum 2004;50:1-4.

32. Ramiro S, Smolen JS, Landewe R, van der Heijde D, Dougados M, Emery P, et al. Pharmacological treatment of psoriatic arthritis: a systematic literature review for the 2015 update of the EULAR recommendations for the management of psoriatic arthritis. Ann Rheum Dis 2016;75:490-8.

33. Gladman DD, Thavaneswaran A, Chandran V, Cook RJ. Do patients with psoriatic arthritis who present early fare better than those presenting later in the disease? Ann Rheum Dis 2011;70:2152-4.

34. Coates LC, Moverley AR, McParland L, Brown S, Navarro-Coy N, O'Dwyer JL, et al. Effect of tight control of inflammation in early psoriatic arthritis (TICOPA): a UK multicentre, open-label, randomised controlled trial. Lancet 2015;386:2489-98.

35. Graudal N, Jurgens G. Similar effects of disease-modifying antirheumatic drugs, glucocorticoids, and biologic agents on radiographic progression in rheumatoid arthritis: meta-analysis of 70 randomized placebo-controlled or drug-controlled studies, including 112 comparisons. Arthritis Rheum 2010;62:2852-63. 